\title{
Impact of Overactive Bladder Step Therapy Policies on Medication Utilization and Expenditures Among Treated Medicare Members
}

\author{
Ibrahim M. Abbass, RPh, PhD; Eleanor O. Caplan, PharmD, PhD; Daniel B. Ng, PharmD, MBA; \\ Rita Kristy, MS; Carol R. Schermer, MD, MPH, FACS; Pamela Bradt, MD, MPH; Jenna M. Collins, MPH; \\ Wai Man Maria Chan, PharmD, MPH; and Brandon T. Suehs, PharmD, PhD
}

\begin{abstract}
BACKGROUND: The impact of formulary management strategies on utilization and expenditures in overactive bladder $(O A B)$ treatment has not been extensively investigated. In 2013, step therapy (ST) policies for 2 branded $O A B$ treatments, mirabegron and fesoterodine, were removed from Humana Medicare Advantage Prescription Drug (MAPD) plans and Medicare prescription drug plans (PDP), allowing for an examination of the effect of ST policies on $O A B$ medication use patterns and costs.
\end{abstract}

OBJECTIVE: To assess the impact of removal of formulary restriction policies for mirabegron and fesoterodine on medication utilization patterns and costs associated with $O A B$ treatment in Medicare patients.

METHODS: A retrospective cross-sectional study design was utilized. Subjects included individuals enrolled in Humana MAPD plans or PDPs, aged $\geq 65$ years, with $\geq 1$ prescription for an OAB medication in 2013 . Patient demographic characteristics, $O A B$ medication utilization, and pharmacy cost trends in 2013 were described. OAB medication use was calculated as the number of 30-day-supply equivalent medication claims and reported as a percentage of the total number of 30-day-supply equivalent claims across all $O A B$ products. $O A B$ medication expenditures were calculated as a percentage of the sum of pharmacy costs for $O A B$ medications and reported separately for each month and drug during 2013. Temporal trends of $O A B$ medication utilization and expenditures in 2013 were calculated using ordinary least squares regression.

RESULTS: Of 194,511 patients, trends in utilization of OAB medications indicated that on average, there was a statistically significant monthly increase in utilization of mirabegron (regression coefficient $[B]=274 ; P<0.001$; 95\% Cl: 218, 330), fesoterodine ( $\mathrm{B}=167 ; P<0.001 ; 95 \% \mathrm{Cl}=129,205)$, oxybutynin extended release (ER; $\mathrm{B}=357 ; P=0.011 ; 95 \% \mathrm{Cl}=99,614)$, and trospium $\mathrm{ER}(\mathrm{B}=33 ; P=0.001 ; 95 \% \mathrm{Cl}=17,50)$ and statistically significant decreases in utilization of solifenacin $(B=-202 ; P=0.048 ; 95 \% \mathrm{Cl}=-402$, -2), tolterodine $\mathrm{ER}(\mathrm{B}=-287 ; P=0.002 ; 95 \% \mathrm{Cl}=-437,-137)$, darifenacin $(\mathrm{B}=-94 ; P<0.001 ; 95 \% \mathrm{Cl}=-128,-61)$, and trospium immediate release (IR; $\mathrm{B}=-22 ; P=0.001 ; 95 \% \mathrm{Cl}=-32,-12$ ). Total $\mathrm{OAB}$ medication expenditures significantly increased an average of $0.12 \%$ for each month during the course of $2013(\mathrm{~B}=0.12 ; P=0.026 ; 95 \% \mathrm{Cl}=0.017,-0.223)$. While monthly oxybutynin IR utilization did not change significantly throughout 2013 $(B=228 ; P=0.169 ; 95 \% \mathrm{Cl}=-114,-570)$, it demonstrated the largest average monthly expenditure increase $(B=0.082 ; P<0.001 ; 95 \% \mathrm{Cl}=0.056$, 0.108 ). When removing oxybutynin IR costs from the total $O A B$ medication costs, the trend in total $O A B$ medication average monthly expenditures was not significant $(\mathrm{B}=0.038 ; P=0.365 ; 95 \% \mathrm{Cl}=-0.051,-0.126)$. An over 4-fold per-unit-cost increase for oxybutynin IR was noted.

CONCLUSIONS: Utilization of 2 branded OAB products increased in the months after ST removal with minimal cost impact. One of the possible reasons total $O A B$ expenditures increased may have been due to the increased cost of the largest-volume generic product, oxybutynin IR.

J Manag Care Spec Pharm. 2017;23(1):27-37

Copyright $\odot 2017$, Academy of Managed Care Pharmacy. All rights reserved.

\section{What is already known about this subject}

Formulary management strategies are often implemented to control medication utilization and expenditures.

Previous research in a broad range of therapeutic areas has shown mixed impacts of step therapy (ST) policies on utilization and costs.

\section{What this study adds}

This study examines the impact of an ST policy in the overactive bladder (OAB) therapy area and among Medicare members.

Removal of ST for 2 branded OAB products in a Medicare population in 2013 resulted in a statistically significant increase in utilization of both products. However, the total utilization for both combined remained lower than $5 \%$ of the total number of $\mathrm{OAB}$ 30-day-supply equivalent medication claims by the end of 2013 . Detailed evaluation of costs showed that the cost per unit of oxybutynin IR, the highest-volume generic product, increased over 4-fold in the last 6 months of 2013, making it one of the possible reasons for the observed increase in total $\mathrm{OAB}$ medication expenditures.

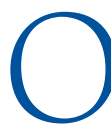
veractive bladder $(\mathrm{OAB})$ is a complex of symptoms characterized by urinary urgency, frequency, and/or nocturia with or without urge incontinence in the absence of an urinary tract infection (UTI) or other obvious pathology. ${ }^{1}$ In 2008, OAB was estimated to affect 455 million individuals worldwide, with an expected $20.1 \%$ increase in individuals affected by 2018, in part due to the increase in the aging population. ${ }^{2}$ According to a 2011 U.S. national crosssectional survey, approximately $27.2 \%$ of men and $43.1 \%$ of women reported $\mathrm{OAB}$ symptoms at least "sometimes." $\mathrm{OAB}$ symptoms without incontinence increase with age in both men and women; however, urge incontinence more commonly affects women at all ages, and particularly as age increases. ${ }^{4}$

OAB has significant effects on clinical, economic, and quality of life outcomes. Patients with $\mathrm{OAB}$ are more likely to experience infections (urinary tract and skin), falls, and fractures and to suffer from depression., 5 The economic burden of OAB is substantial, with 2007 annual per capita direct and indirect costs for an individual with OAB estimated at $\$ 1,925$ in the United States. This equated to approximately $\$ 66$ billion in total national costs for this condition in the United States alone, 
with expenditures increasing and projected to reach $\$ 82.6$ billion in 2020. ${ }^{7}$ More specifically, in 2000, treatment-related costs due to urinary incontinence in community-dwelling patients were estimated at $\$ 210$ million annually. ${ }^{8}$ Additionally, $\mathrm{OAB}$ can contribute negatively to a person's quality of life, including effects on sleep, work, and activities of daily living., ${ }^{9,10}$

First-line treatment recommendations for $\mathrm{OAB}$ include behavioral therapies, such as bladder training, control strategies, pelvic floor training, and fluid management. Pharmacotherapy is second-line therapy, with pharmacological agents often used in combination with behavioral therapies. The pharmacotherapies recommended include either antimuscarinics or a $\beta 3$-adrenergic agonist. ${ }^{1}$ Antimuscarinic agents, such as oxybutynin, tolterodine, fesoterodine, solifenacin, darifenacin, and trospium, have been shown to reduce symptoms of OAB and are generally well tolerated, but they are also commonly associated with anticholinergic side effects (e.g., dry mouth, constipation, urinary retention, impaired cognitive function). ${ }^{1}$

In order for health plans to control costs and utilization, new medications are often subject to formulary and utilization management policies, such as step therapies (STs), prior authorization, cost-sharing, quantity limits, and preferred drug lists. A review by Motheral et al. (2011) summarized the results of 14 studies where ST interventions were implemented. ${ }^{11}$ These studies were conducted in commercial or Medicaid plan enrollees and the therapeutic areas of focus were antidepressants, antihypertensives, antipsychotics, nonsteroidal anti-inflammatory agents, and proton pump inhibitors. Drug savings were achieved across all therapeutic classes, except antipsychotics, as a result of greater use of lower-cost alternatives and from decreases in utilization. ${ }^{11}$ Some studies have reported a negative impact of ST policies on outcomes, such as treatment discontinuation and decreased medication adherence..$^{12-14}$ Despite some recent publications regarding ST impacts, limited evidence exists in regard to ST impacts on utilization and costs in other therapy areas and in the Medicare population in particular. ${ }^{11-13}$

In the OAB therapy area, Humana had implemented ST formulary policies across Medicare plans that required treatment with 2 antimuscarinic medications (including oxybutynin and trospium) prior to approval of a prescription claim for 2 branded products, fesoterodine and mirabegron. Fesoterodine, an antimuscarinic approved in the United States in 2008, has once-daily and flexible dosing with demonstrated safety and efficacy. ${ }^{15}$ Mirabegron, launched in the United States in late 2012, is the only $\beta 3$-adrenergic receptor agonist that is approved by the Food and Drug Administration for the treatment of OAB.$^{16}$ The ST policy for fesoterodine was removed in May 2013 and for mirabegron in July of 2013, thus providing an opportunity to examine utilization and costs of OAB products during periods of restricted and open access. There were no other ST policies in place in the OAB therapy area during this time frame.
The purpose of this research was to examine trends in $\mathrm{OAB}$ medication utilization and prescription costs and to assess the impact of formulary restriction policies for mirabegron and fesoterodine and their subsequent removal on medication utilization patterns and costs associated with OAB treatment in Medicare beneficiaries.

\section{Methods}

\section{Study Design}

A retrospective cross-sectional study was conducted including both Medicare Advantage Prescription Drug (MAPD) plans and Part D prescription drug plan (PDP) members who had least 1 medication claim for any OAB medication: oxybutynin immediate release (IR) and oxybutynin extended release (ER; (Generic Product Identifiers [GPIs] 54000030, 54100045); tolterodine IR and tolterodine ER (GPIs 54000070, 54100060); fesoterodine (GPI 54100020); mirabegron (GPI 54200050); solifenacin (GPI 54100055); trospium IR and trospium ER (GPIs 54000075, 54100065); and darifenacin (GPIs 54000017, 54100010) between January 1, 2013, and December 31, 2013. All members were required to be aged 65 years or older as of January 1, 2013. The study time frame (calendar year 2013) was selected to provide roughly equivalent periods of restricted and open access given the timing of the ST policies being removed (July 2013 for mirabegron and May 2013 for fesoterodine). In addition, the observation period was constrained to a single Medicare plan year to minimize the impact of changes to benefits and/or formularies that may occur across different plan years and to attempt to isolate the impact of the formulary changes within a specific plan year. In order to resolve monthto-month trends, OAB medication utilization and health care costs were examined in monthly cross sections of utilizing members. In order to be included in each monthly cross section, the member was required to have a prescription claim for an $\mathrm{OAB}$ medication observed during the given month. Continuous enrollment was not required, and given the crosssectional design on a monthly basis, treatment-naïve patients, treatment switchers, continuers, and discontinuers may be included within a given monthly time frame. The study data were extracted from the Humana database, which contains integrated medical and pharmacy claims, representing nearly 12 million total health plan members in 2013, with broad geographic representation. ${ }^{17}$ Given the proprietary nature of the drug-specific financial and utilization data included in the analysis, all financial and drug-specific utilization results are presented in relative terms as described in the Study Measures section. In order to examine relative trends in expenditures over the course of the plan year, January was selected as the reference month. Members of groups that contractually restrict the use of administrative claims data for research purposes were not eligible for inclusion in the study. 


\section{Study Measures}

In order to assess the impact of removing the ST policies, monthly shifts in demographic characteristics, OAB medication utilization, and $\mathrm{OAB}$ medication expenditures were tracked. OAB medication utilization was measured by calculating the number of 30-day-supply equivalent medication claims. The generic dispensing rate was also calculated. Two measures were used to track expenditures for each medication in the $\mathrm{OAB}$ therapeutic area: (1) expenditures per utilizing member per month (PUMPM) and (2) the percentage of total annual $\mathrm{OAB}$ drug spend by medication by month. In the primary analysis, expenditure measures (PUMPM and percentage of total spend) included both member- and plan-paid components. A sensitivity analysis was also conducted where drug expenditures were measured using only the plan-paid cost component. The PUMPM tracks specific medication expenditures after accounting for the utilization of all $O A B$ drugs and is calculated using the following formula:

PUMPM $=\frac{\sum R x \text { expenditures }}{\text { Total number of members on OAB medications }}$

After calculating the PUMPM, the results were reported as percent changes from the January 2013 PUMPM (baseline).

The percentage of total $\mathrm{OAB}$ drug spend was calculated for each medication and for each month using the following formula:

\section{$R x$ expenditure}

Percentage of total annual spend $=\frac{\text { for drug during given } \text { month }}{\text { Grand total of } 2013}$

$O A B$ drug spend

Additionally, the 30-day-supply equivalent average wholesale acquisition cost (WAC) for each $\mathrm{OAB}$ medication was assessed to explore and rule out the confounding effect of $O A B$ medication acquisition costs on $\mathrm{OAB}$ medication expenditures in 2013. Prior to study initiation, the research protocol was reviewed and approved by an independent institutional review board, and waivers of informed consent and Health Insurance Portability and Accountability Act authorization were obtained.

\section{Statistical Analysis}

Descriptive statistics, such as means and standard deviations and/or median and interquartile ranges, were calculated for continuous variables, and frequency counts and percentages were calculated for categorical variables. The temporal trends in OAB medication utilization and spend in 2013 were examined through calculating the slope coefficients (nonstandardized) for each drug. Ordinary least square (OLS) regression models were used to obtain the slopes (regression coefficients $[\mathrm{B}]$ ), which measure the average monthly changes in OAB spend and/or utilization during 2013), $P$ values, and 95\% confidence intervals (CIs). Individual models were fit for

\begin{tabular}{|c|c|c|}
\hline $\begin{array}{ll}\text { TABLE 1 Demc } & \text { OAB } \\
& \text { OAB }\end{array}$ & ic Chara & ics of Overall \\
\hline Variables & Count & Percentage, $\%$ \\
\hline Number of unique members & 194,511 & 100.0 \\
\hline Age, mean (SD) & $75.6(6.9)$ & - \\
\hline \multicolumn{3}{|l|}{ Gender } \\
\hline Female & 145,583 & 74.8 \\
\hline Male & 48,928 & 25.2 \\
\hline \multicolumn{3}{|l|}{ Race } \\
\hline White & 167,106 & 85.9 \\
\hline Black & 15,389 & 7.9 \\
\hline Hispanic & 4,148 & 2.1 \\
\hline Other & 7,868 & 4.0 \\
\hline \multicolumn{3}{|l|}{ Region } \\
\hline Midwest & 51,066 & 26.3 \\
\hline Northeast & 13,815 & 7.1 \\
\hline South & 97,059 & 49.9 \\
\hline West & 32,571 & 16.7 \\
\hline \multicolumn{3}{|l|}{ Health plan } \\
\hline PDP & 116,574 & 59.9 \\
\hline MAPD & 77,937 & 40.1 \\
\hline Low-income subsidy & 61,273 & 31.5 \\
\hline Dual-eligible & 49,393 & 25.4 \\
\hline
\end{tabular}

each medication separately and for all OAB medications combined. The regressed variables in these OLS models included (a) the monthly $\mathrm{OAB}$ utilization (30-day equivalent medication claims) and (b) the monthly percentage of total annual $\mathrm{OAB}$ drug spend. When interpreting the results of the utilization measure models, for example, a $\mathrm{B}=200$ would indicate, on average, a monthly increase of 20030 -day equivalent medication claims. For the percentage spend measure, a regression coefficient of 0.1 would indicate an average monthly increase of $0.1 \%$ for a given medication out of the total annual $\mathrm{OAB}$ drug spend. Additional post hoc exploratory analyses were conducted after review of the results of the planned analyses described above. A series of analyses regressed total monthly $O A B$ medication spend after individually excluding expenditures for oxybutynin IR, solifenacin, mirabegron, and fesoterodine. Expenditure results were also subject to sensitivity analyses wherein the net paid amount by the health plan only was evaluated. All analyses were conducted using SAS Enterprise Guide 5.1 (SAS Institute, Cary, NC).

\section{Results}

There were 252,590 MAPD or PDP members who had an OAB medication claim in 2013. Of those, 58,079 (23.0\%) members were excluded for not meeting the age criterion, resulting in a total of study cohort of 194,511 (77.0\%) members. Table 1 


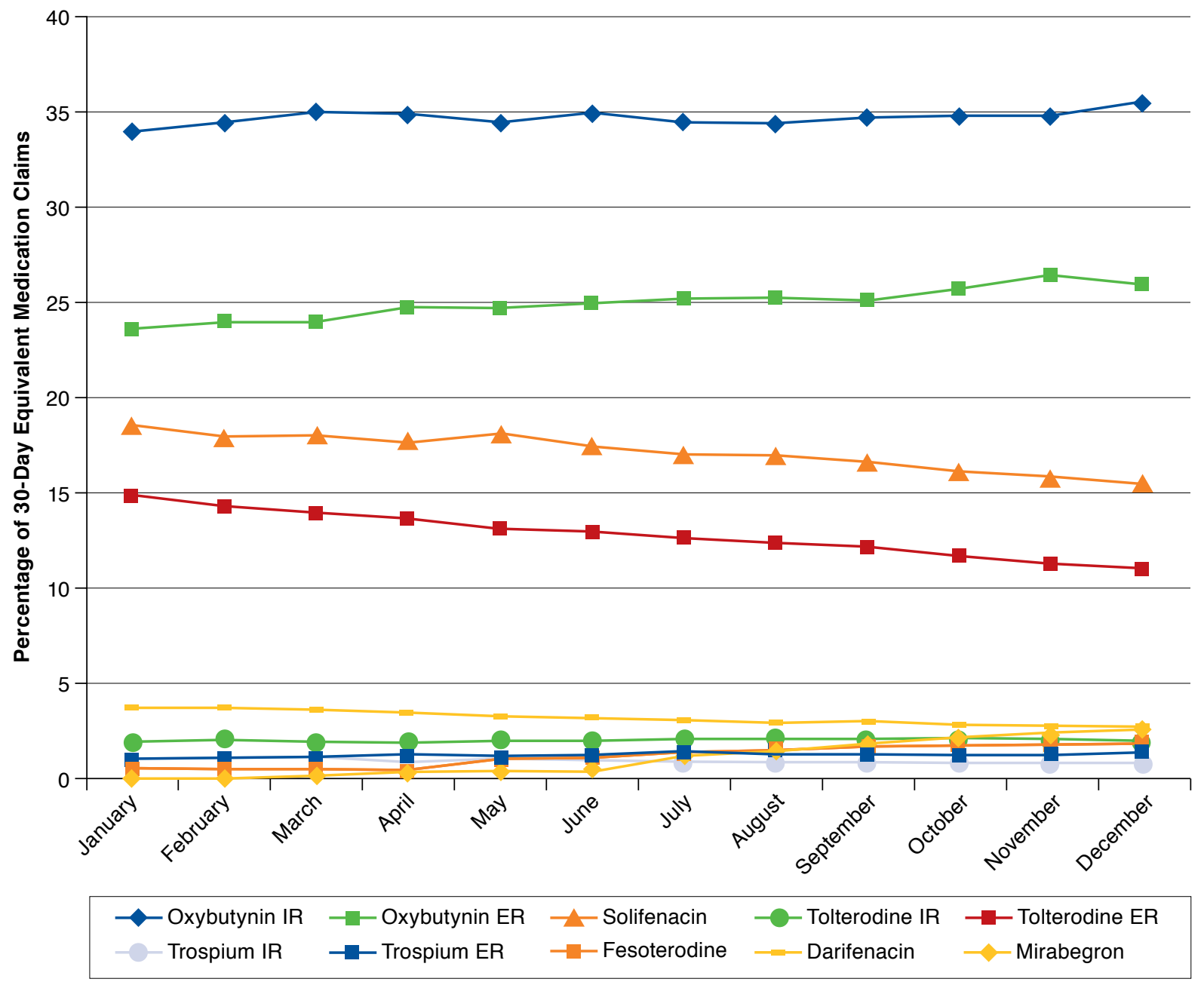

$E R=$ extended release; $I R=$ immediate release.

displays the demographic characteristics of members included in the analysis. The majority of patients were female (74.8\%), with an average age of 75.6 years ( $\mathrm{SD} \pm 6.9)$. Most patients were from the South (49.9\%), followed by Midwest (26.3\%), West (16.7\%), and Northeast (7.1\%). White was the dominant racial/ ethnic group (85.9\%), followed by black (7.9\%), other races (4.0\%), and Hispanic (2.1\%). Almost two thirds of the sample had a PDP only (59.9\%), while the rest of the sample had coverage under an MAPD plan. One third of the sample received low-income subsidy (31.4\%), while $25.4 \%$ were dual-eligible. Shifts in the monthly patient demographic characteristics were not observed (data not shown).

\section{OAB Medication Utilization}

The number of members with an $\mathrm{OAB}$ medication claim and total number of $\mathrm{OAB}$ medication claims remained relatively consistent throughout 2013, though there was some evidence of seasonality. The number of members with any OAB medication claim was lowest in February $(n=63,854)$ and highest in October $(n=73,062)$. The total number of OAB medication claims closely mirrored the number of members with any $\mathrm{OAB}$ medication claim, with the lowest numbers in February $(67,348)$ and the highest in October $(79,388)$. The generic dispense rate was over $50 \%$ across all months but increased by over 4\% from January (58.0\%) to December (62.0\%; see Appendix, available in online article). 


\begin{tabular}{|c|c|c|c|c|c|}
\hline \multirow[b]{2}{*}{ Product } & \multirow{2}{*}{$\begin{array}{l}\text { Number of 30-Day } \\
\text { Equivalent Medication } \\
\text { Claims at Baseline }\end{array}$} & \multirow{2}{*}{$\begin{array}{c}\text { Regression } \\
\text { Coefficient }(\mathrm{B})^{\mathrm{b}}\end{array}$} & \multicolumn{2}{|c|}{$95 \%$ CI } & \multirow[b]{2}{*}{$P$ Value } \\
\hline & & & Lower CI & Upper CI & \\
\hline Total OAB Rx utilization & 111,529 & 476 & -563 & 1,515 & 0.331 \\
\hline Oxybutynin IR & 38,015 & 228 & -114 & 570 & 0.169 \\
\hline Oxybutynin ER & 26,453 & 357 & 99 & 614 & 0.011 \\
\hline Solifenacin & 20,818 & -202 & -402 & -2 & 0.048 \\
\hline Tolterodine IR & 2,235 & 22 & -1 & 44 & 0.058 \\
\hline Tolterodine ER & 16,581 & -287 & -437 & -137 & 0.002 \\
\hline Trospium IR & 1,175 & -22 & -32 & -12 & 0.001 \\
\hline Trospium ER & 1,193 & 33 & 17 & 50 & 0.001 \\
\hline Fesoterodine & 669 & 167 & 129 & 205 & $<0.001$ \\
\hline Darifenacin & 4,245 & -94 & -128 & -61 & $<0.001$ \\
\hline Mirabegron & 145 & 274 & 218 & 330 & $<0.001$ \\
\hline
\end{tabular}

Note: Results for each medication (or medication group) reflect a separate regression model. The outcome variable for each model was monthly OAB utilization (30-day equivalent medication claims).

ajanuary 2013.

${ }^{b}$ Monthly change averaged over 2013.

$C I=$ confidence interval; $E R=$ extended release; $I R=$ immediate release; $O A B=$ overactive bladder $R x=$ prescription.

Oxybutynin IR 30-day-supply equivalent claims were the highest across all OAB medications in 2013 (range: 34.1\%35.6\%). Figure 1 displays the utilization of each product as a percentage of the total 30-day equivalent $\mathrm{OAB}$ medication claims on a monthly basis. The utilization of oxybutynin IR, and, to a lesser degree, tolterodine IR remained relatively constant, while a declining trend in utilization was observed for tolterodine ER (14.9\% in January to $11.1 \%$ in December), darifenacin (3.8\% in January to $2.8 \%$ in December), trospium IR (1.1\% in January to $0.8 \%$ in December), and solifenacin (18.7\% in January to $15.6 \%$ in December). Oxybutynin ER (23.7\% in January to $26.1 \%$ in December), trospium ER (1.1\% in January to $1.4 \%$ in December), fesoterodine (0.6\% in January to $1.9 \%$ in December), and mirabegron (0.1\% in January to $2.6 \%$ in December) showed an increase in their utilization in 2013.

Table 2 summarizes the temporal month-to-month trends of the 30-day-supply equivalent OAB medications. The results indicated that on average, the monthly increase in utilization of the total $O A B$ medication throughout 2013 did not significantly change $(B=476 ; P=0.331 ; 95 \% C I=-563,1,515)$. The utilization of oxybutynin IR and tolterodine IR also did not significantly change $(P=0.169$ and $P=0.058$, respectively). The largest significant decreases in utilization were observed for tolterodine ER $(B=-287 ; P=0.002 ; 95 \% C I=-437,-137)$, followed by solifenacin $(B=-202 ; P=0.048 ; 95 \% C I=-402$, -2), darifenacin $(B=-94 ; P<0.001 ; 95 \% C I=-128,-61)$, and trospium IR ( $B=-22 ; P=0.001 ; 95 \% C I=-32,-12)$. Significant increases in utilization during 2013 were observed for oxybutynin $E R(B=357 ; P=0.011 ; 95 \% C I=99,614)$, followed by mirabegron $(B=274 ; P<0.001 ; 95 \% C I=218,330)$, fesoterodine
$(B=167 ; P<0.001 ; 95 \% C I=129,205)$, and trospium $\mathrm{ER}(\mathrm{B}=33$; $P=0.001 ; 95 \% C I=17,50)$.

\section{OAB Medication Expenditures}

A similar trend was noted with PUMPM expenditures for OAB prescriptions as with the utilization trends, and trends were similar whether PUMPM was calculated as gross expenditures (plan- plus member-paid amounts) or net expenditures (planpaid amount only). The gross PUMPM (net plan-paid PUMPM) was lowest in February, $7.1 \%$ (6.1\%) lower than baseline (January 2013), and increased by $9.7 \%$ (9.9\%) from June to July and by $12.0 \%$ (12.0\%) from June to August. The change in PUMPM from the beginning of the year to the end was $4.1 \%$ (2.7\%; Appendix).

Figure 2 displays the percentage of the total OAB medication expenditures on a monthly basis by product. Solifenacin had the highest percentage of total monthly OAB medication expenditures consistently throughout the year (range: $34.0 \%$ $41.6 \%$ ), followed by tolterodine ER (range: $24.5 \%-31.8 \%$ ), and oxybutynin ER (range: 9.3\%-12.0\%). Oxybutynin IR increased from $2.9 \%$ of total expenditures to $10.7 \%$ in December and had the largest month-to-month increase in expenditures, despite relatively stable utilization over the study period. Increases in expenditures from January to December were noted for mirabegron (0.3\% in January to $6.4 \%$ in December), fesoterodine (1.1\% in January to $3.4 \%$ in December), trospium ER (1.0\% in January to $1.4 \%$ in December), and tolterodine IR (2.8\% in January to $2.9 \%$ in December). Meanwhile, the expenditures of oxybutynin ER (range: $9.3 \%$ 12.2\%), solifenacin (range: $34.0 \%-41.6 \%$ ), and tolterodine ER 


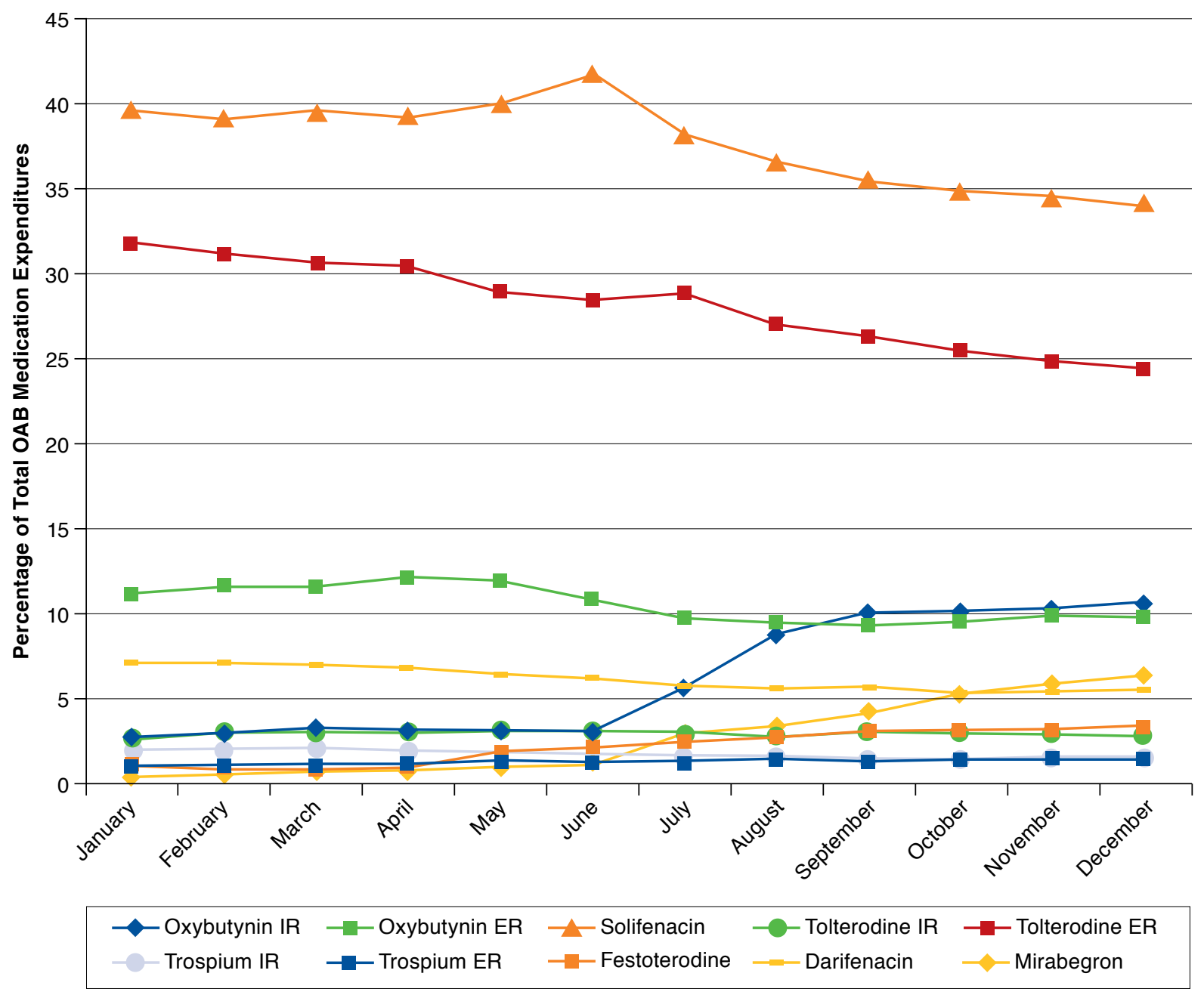

ER=extended release; $I R=$ immediate release; $O A B=$ overactive bladder.

(range: $24.5 \%-31.8 \%)$ remained relatively stable. Both darifenacin (7.2\% in January to $5.4 \%$ in December) and trospium IR $(2.0 \%$ in January to $1.5 \%$ in December) showed a relatively constant downward trend in expenditures. Sensitivity analyses were conducted with the plan-paid only costs. The percentage of cost that oxybutynin ER contributed to the total OAB expenditures was approximately 2\%-4\% lower across months in the net plan-paid amount (range: 7.1\%-9.0\%) compared with the net plan-paid and patient-paid amounts (range: 9.3\%-12.2\%). Conversely, the percentage of solifenacin and tolterodine ER costs contributing to the total $\mathrm{OAB}$ expenditures increased between $1.0 \%$ and $3.5 \%$ across all months for both products (solifenacin range: $35.5 \%-44.6 \%$ and tolterodine ER range:
25.5\%-34.5\%) in the net plan-paid analyses compared with the analysis including both plan and patient costs.

Table 3 summarizes the temporal month-to-month trend in $\mathrm{OAB}$ medication expenditures as a percentage of total annual spend. The results indicated that in January, spend on $\mathrm{OAB}$ medication represented $8.6 \%$ of the total OAB annual medication spend in 2013. Spend increased an average of $0.120 \%$ for each month during the course of $2013(B=0.120 ; P=0.026 ; 95 \%$ $\mathrm{CI}=0.017,0.223)$. Even though the utilization of oxybutynin IR did not significantly change throughout 2013, it demonstrated the largest month-to-month increasing trend in total expenditures ( $\mathrm{B}=0.082 ; P<0.001 ; 95 \% \mathrm{CI}=0.056,0.108)$. When oxybutynin IR costs were excluded in a sensitivity analysis, the increase in total $\mathrm{OAB}$ medication average monthly spend 
TABLE 3 Baseline and Temporal Average Monthly Change in Percentage of Total Annual OAB Medication Expenditures in 2013

\begin{tabular}{|c|c|c|c|c|c|c|c|c|c|c|}
\hline \multirow[b]{3}{*}{ Product } & \multicolumn{5}{|c|}{ Plan- and Patient-Paid Expenditure Analysis } & \multicolumn{5}{|c|}{ Plan-Paid Only Expenditure Analysis } \\
\hline & \multirow{2}{*}{$\begin{array}{c}\text { OAB } \\
\text { Expenditure } \\
\text { at Baselinea }\end{array}$} & \multirow[b]{2}{*}{$\begin{array}{l}\text { Coefficient } \\
\text { (B) }\end{array}$} & \multicolumn{2}{|c|}{$95 \% \mathrm{CI}$} & \multirow[b]{2}{*}{$P$ Value } & \multirow{2}{*}{$\begin{array}{c}\mathrm{OAB} \\
\text { Expenditure } \\
\text { at Baseline }\end{array}$} & \multirow{2}{*}{$\begin{array}{l}\text { Regression } \\
\text { Coefficient } \\
\text { (B) }\end{array}$} & \multicolumn{2}{|c|}{$95 \% \mathrm{CI}$} & \multirow[b]{2}{*}{$P$ Value } \\
\hline & & & Lower CI & Upper CI & & & & Lower CI & Upper CI & \\
\hline Total OAB medication costs & 8.577 & 0.120 & 0.017 & 0.223 & 0.026 & 8.529 & 0.118 & 0.019 & 0.217 & 0.024 \\
\hline $\begin{array}{l}\text { OAB medication costs } \\
\text { (excluding oxybutynin IR) }\end{array}$ & 8.328 & 0.038 & -0.051 & 0.126 & 0.365 & 8.325 & 0.023 & -0.061 & 0.106 & 0.560 \\
\hline $\begin{array}{l}\text { OAB medication costs } \\
\text { (excluding solifenacin) }\end{array}$ & 3.401 & 0.125 & 0.051 & 0.199 & 0.004 & 4.850 & 0.137 & 0.065 & 0.209 & 0.002 \\
\hline Oxybutynin IR & 0.249 & 0.082 & 0.056 & 0.108 & $<0.001$ & 0.204 & 0.095 & 0.066 & 0.125 & $<0.001$ \\
\hline Oxybutynin ER & 0.963 & -0.007 & -0.017 & 0.003 & 0.170 & 0.612 & 0.004 & -0.004 & 0.012 & 0.294 \\
\hline Solifenacin & 3.401 & -0.005 & -0.042 & 0.032 & 0.775 & 3.680 & -0.019 & -0.058 & 0.020 & 0.301 \\
\hline Tolterodine IR & 0.242 & 0.003 & 0.0002 & 0.005 & 0.039 & 0.239 & 0.001 & -0.001 & 0.004 & 0.247 \\
\hline Tolterodine ER & 2.723 & -0.025 & -0.056 & 0.007 & 0.109 & 2.942 & -0.037 & -0.069 & -0.004 & 0.032 \\
\hline Trospium IR & 0.172 & -0.003 & -0.005 & -0.002 & 0.001 & 0.141 & -0.002 & -0.004 & -0.001 & 0.003 \\
\hline Trospium ER & 0.090 & 0.004 & 0.003 & 0.006 & $<0.001$ & 0.062 & 0.005 & 0.004 & 0.007 & $<0.001$ \\
\hline Fesoterodine & 0.095 & 0.025 & 0.019 & 0.030 & $<0.001$ & 0.089 & 0.021 & 0.017 & 0.026 & $<0.001$ \\
\hline Darifenacin & 0.615 & -0.009 & -0.014 & -0.004 & 0.003 & 0.534 & -0.003 & -0.008 & 0.002 & 0.210 \\
\hline Mirabegron & 0.027 & 0.054 & 0.043 & 0.066 & $<0.001$ & 0.026 & 0.051 & 0.041 & 0.062 & $<0.001$ \\
\hline
\end{tabular}

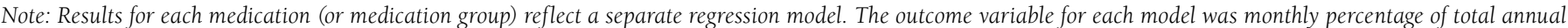
$O A B$ drug spend.

January 2013.

$C I=$ confidence interval; $E R=$ extended release $I R=$ immediate release; $O A B=$ overactive bladder

was no longer significant $(B=0.038 ; P=0.365 ; 95 \% C I=-0.051$, 0.126). Additionally, when excluding the product with the highest percentage of total expenditures (solifenacin) from the model, the month-to-month increasing trend remained significant $(B=0.137 ; P=0.002 ; 95 \% C I=0.065,0.209)$. Meanwhile, the spend associated with oxybutynin ER, solifenacin, and tolterodine ER remained consistent (all $P$ values $>0.05$ ). Other products with increases in month-to-month spend in 2013 were mirabegron ( $B=0.054 ; P<0.001 ; 95 \% C I=0.043,0.066)$, fesoterodine $(B=0.025 ; P<0.001 ; 95 \% C I=0.019,0.033)$, trospium $E R(B=0.004 ; P<0.001 ; 95 \% C I=0.003,0.006)$, and tolterodine IR $(B=0.003 ; P=0.039 ; 95 \% C I=0.0002,0.005)$. Both darifenacin $(B=-0.009 ; P=0.003 ; 95 \% C I=-0.014,-0.004)$ and trospium IR ( $\mathrm{B}=-0.003 ; P=0.001 ; 95 \% \mathrm{CI}=-0.005,-0.002)$ showed a month-to-month decreasing trend in total expenditures. A sensitivity analysis was conducted using net paid amount by the health plan as the expenditure measure. The direction of the regression coefficients remained consistent when net plan-paid amount was modeled compared with the plan- and patient-paid model; however, the coefficient was no longer statistically significant in the plan-paid only model for tolterodine IR $(B=0.001 ; P=0.247 ; 95 \% C I=-0.001,0.004)$ and the expenditure model for darifenacin $(B=-0.003 ; P=0.210$; $95 \% \mathrm{CI}=-0.008,-0.002)$. Conversely, the decline in monthto-month expenditures for tolterodine ER became statistically significant in the plan-paid only model $(B=-0.037 ; P=0.032$; $95 \% \mathrm{CI}=-0.069,-0.004)$.
Upon further examination of the monthly average WAC for $\mathrm{OAB}$ medications, the majority of $\mathrm{OAB}$ medications did not experience unit cost increases during 2013, except for oxybutynin IR, where a 4-fold increase in unit cost was observed. While most products had only slight fluctuations $( \pm 10 \%)$ throughout the year, oxybutynin IR had a greater than 500\% increase in the 30-day-supply equivalent WAC from January to December ( $\$ 4.40$ to $\$ 27.60$ ), with the most notable increase occurring between September and October. These trends were mirrored in oxybutynin IR spend where oxybutynin IR contributed to less than 3\% of total expenditures in January but almost $11 \%$ by December, despite a stable number of claims, days supply, and number of members utilizing that product through the year.

\section{Discussion}

ST utilization management policies are intended to ensure that lower-cost, therapeutically equivalent medications are attempted prior to initiation of more expensive medication treatment. ${ }^{11,12}$ ST policies are typically implemented on branded formulations in therapeutic areas where low-cost generic products also exist. Studies in a variety of therapeutic areas have consistently demonstrated that ST policies are effective at reducing utilization of the targeted medication. ${ }^{11,12}$ This effect is the result of a financial barrier to access, enforced via a hard edit that halts adjudication of the prescription claim at the point of sale. In response to such a coverage denial, the 
member may request that the prescriber change the order to the preferred agent, appeal to the health plan for an exception to the policy, pay the full retail cost of the medication, or abandon treatment. ${ }^{18}$ When an ST policy is newly implemented, the resulting impact is a rapid decrease in utilization of the targeted medication. ${ }^{19-23}$ In the current study, short-term utilization trends associated with the removal of existing ST policies in the $\mathrm{OAB}$ therapy area were examined, which would thereby remove a barrier to medication access for the targeted drugs. The results of this analysis indeed showed that mirabegron and fesoterodine utilization increased in the second half of 2013 when the ST policies for these products were no longer in place, and shifts in utilization of the other $O A B$ medications were additionally noted.

While the impact on medication utilization is relatively straightforward, the impact of ST policies on overall expenditures may be more nuanced. Shifts in drug expenditures coinciding with revisions to utilization management policies may be simultaneously affected by a variety of factors. This study noted increased expenditures on the $\mathrm{OAB}$ therapeutic area during the course of 2013. Fesoterodine and mirabegron contributed to the overall $\mathrm{OAB}$ medication cost increases after step therapy removal, and these costs were proportional to the increase in utilization. The highest-volume drug, oxybutynin IR, also contributed to the overall increase in OAB drug expenditures. It was noted that the increase in expenditures for oxybutynin IR was not associated with corresponding changes in utilization throughout the year, and utilization of this product remained relatively constant. Exploring this factor further led to the discovery of the substantial increase in drug cost of the highest-volume generic product in the therapeutic area. These findings highlight that evaluation of the general impact of an ST policy should include examination of utilization and expenditures for the individual medications within the therapeutic area. Examination of only the medication targeted by the ST policy, or only the overall therapeutic class drug spend, may obscure meaningful trends in utilization and medication expenditures within the class.

Though branded products are often the focus of drug price increases, generic drug pricing increases have been a topic of recent industry and congressional discussion and concern, with the press calling considerable national attention to this issue and multiple examples of these generic drug price increases being publicized. ${ }^{24-26} \mathrm{~A}$ senate hearing cited the growth in the cost of generic medications, with at least a 50\% increase in cost in almost 20\% of the top generic drug products in 1 year, with oxybutynin seeing a $130 \%$ price increase (December 2012 to December 2013). ${ }^{27}$ Continual monitoring and vigilance of economic and clinical outcomes of generic products is warranted by health care decision makers.

Further examination of potential marketplace dynamics in 2013 that could have influenced the increase in the cost of this highly utilized product could help clarify these results.
There could be additional factors, aside from the increase in oxybutynin IR cost, that may have contributed to increased costs observed throughout the year. Seasonality may be a factor where toward the end of the year, a greater number of patients may be reaching pharmacy and medical coverage limits, not only placing more financial burden on the health plan but also potentially introducing additional moral hazard (i.e., patients have fewer financial barriers that potentially increase their overall health care consumption). Overall health care cost inflation for the year could have also contributed to these increases. Finally, the costs included in this study entailed direct pharmacy costs and did not include indirect costs that could be associated with individual drugs. Further research is necessary to evaluate individual cohorts of patients by OAB drug and compare their associated outcomes and costs.

\section{Limitations}

The results of this study need to be considered in light of its limitations. As with any study utilizing administrative claims data, there may be incomplete data or errors in claims submission or coding. Additionally, no causal inference could be ascertained, as it was observational. Despite the large Humana membership, this study only used data from 1 managed care organization. While the gender distribution in the current study was typical of medication treating OAB patients, ${ }^{3,28,29}$ the age, geographic distribution, and race/ethnicity makeup reflect the health plan membership and geographic footprint. The results of this study may not be generalizable to populations outside of the health plan, to other Medicare and non-Medicare populations, or to plans operating in different geographical regions. This study was limited to a single plan year and the findings may differ over longer time frames and in later plan years as medication use patterns and drug pricing evolve. In addition, this study was based on analysis of a subset of MAPD and PDP members whose data were eligible for research purposes; thus, the utilization and expenditure data do not reflect the totality of health plan membership. Finally, this analysis primarily provided information on unadjusted trends in $\mathrm{OAB}$ medication prescribing behavior and changes in cost and did not control for potential confounders that could influence results. However, as the patient cohort demographic characteristics remained relatively consistent throughout 2013, further adjustments were not deemed to be warranted.

\section{Conclusions}

As expected, an increase in the use of mirabegron and fesoterodine in this population of Medicare OAB patients was observed after the ST policies were removed. At the same time, costs increased. However, examination of trends in individual medication use and expenditures suggests that a key factor in the increase of overall expenditures was the considerable increase in cost for the highest-volume generic product. 


\section{Authors}

IBRAHIM M. ABBASS, RPh, PhD; ELEANOR O. CAPLAN, PharmD, PhD; JENNA M. COLLINS, MPH; and BRANDON T. SUEHS, PharmD, PhD, Comprehensive Health Insights, Louisville, Kentucky. DANIEL B. NG, PharmD, MBA; RITA KRISTY, MS; CAROL R. SCHERMER, MD, MPH, FACS; and PAMELA BRADT, MD, MPH, Astellas Pharma Global Development, Northbrook, Illinois. WAI MAN MARIA CHAN, PharmD, MPH, Humana Pharmacy Solutions, Louisville, Kentucky.

AUTHOR CORRESPONDENCE: Eleanor O. Caplan, PharmD, PhD, 515 W. Market St., 7th Fl., Louisville, KY 40202. Tel.: 502.476.4557; Fax: 502.322.8453; E-mail: ecaplan@humana.com.

\section{DISCLOSURES}

This research was funded by Astellas Pharma Global Development and was conducted as part of the Astellas-Humana Research Collaboration. Ng, Kristy, Schermer, and Bradt are employees of Astellas. Astellas manufactures mirabegron (Myrbetriq) and solifenacin (VESIcare). Abbass, Caplan, Collins, and Suehs are employees of Comprehensive Health Insights, a subsidiary of Humana, which received funding from Astellas for this study. Suehs owns stock in Humana. Chan is an employee of Humana Pharmacy Solutions.

Portions of this study were presented as a poster at Academy of Managed Care Pharmacy Nexus 2015; October 26-29, 2015; Orlando, Florida.

Study concept and design were contributed by $\mathrm{Ng}$, Chan, Suehs, and Abbass, along with Collins. Abbass took the lead in data collection, along with Collins and with assistance from Caplan, Chan, and Suehs. Data interpretation was provided by Kristy and Bradt, along with Abbass, Caplan, Ng, Suehs, Collins, and Chan. The manuscript was written primarily by Caplan, along with Schermer, Suehs, and Abbass, and revised by Caplan, Schermer, and Ng, along with the other authors.

\section{REFERENCES}

1. Gormley EA, Lightner DJ, Burgio KL, et al. Diagnosis and treatment of overactive bladder (non-neurogenic) in adults: AUA/SUFU guideline. May 2014. Available at: https://www.auanet.org/common/pdf/education/clinicalguidance/Overactive-Bladder.pdf. Accessed December 10, 2016.

2. Irwin DE, Kopp ZS, Agatep B, Milsom I, Abrams P. Worldwide prevalence estimates of lower urinary tract symptoms, overactive bladder, urinary incontinence and bladder outlet obstruction. BJU Int. 2011;108(7):1132-38.

3. Coyne KS, Sexton CC, Vats V, Thompson C, Kopp ZS, Milsom I. National community prevalence of overactive bladder in the United States stratified by sex and age. Urology. 2011;77(5):1081-87.

4. Stewart WF, Van Rooyen JB, Cundiff GW, et al. Prevalence and burden of overactive bladder in the United States. World J Urol. 2003;20(6):327-36.

5. Darkow T, Fontes CL, Williamson TE. Costs associated with the management of overactive bladder and related comorbidities. Pharmacotherapy. 2005;25(4):511-19.

6. Wagner TH, Hu TW, Bentkover J, et al. Health-related consequences of overactive bladder. Am J Manag Care. 2002;8(19 Suppl):S598-607.

7. Ganz ML, Smalarz AM, Krupski TL, et al. Economic costs of overactive bladder in the United States. Urology. 2010;75(3):526-32, 532, e521-518.

8. Hu TW, Wagner TH, Bentkover JD, Leblanc K, Zhou SZ, Hunt T. Costs of urinary incontinence and overactive bladder in the United States: a comparative study. Urology. 2004;63(3):461-65.

9. Abrams P, Kelleher CJ, Kerr LA, Rogers RG. Overactive bladder significantly affects quality of life. Am J Manag Care. 2000;6(11 Suppl):S580-90.
10. Coyne KS, Sexton CC, Irwin DE, Kopp ZS, Kelleher CJ, Milsom I. The impact of overactive bladder, incontinence and other lower urinary tract symptoms on quality of life, work productivity, sexuality and emotional well-being in men and women: results from the EPIC study. BJU Int. 2008;101(11):1388-95.

11. Motheral BR. Pharmaceutical step-therapy interventions: a critical review of the literature. J Manag Care Pharm. 2011;17(2):143-55. Available at: http:// www.jmcp.org/doi/abs/10.18553/jmcp.2011.17.2.143.

12. Shoemaker SJ, Pozniak A, Subramanian R, Mauch D. Effect of 6 managed care pharmacy tools: a review of the literature. J Manag Care Pharm. 2010;16(6 Suppl A):S3-20. Available at: http://www.jmcp.org/doi/ abs/10.18553/jmcp.2010.16.S6-A.1.

13. Happe LE, Clark D, Holliday E, Young T. A systematic literature review assessing the directional impact of managed care formulary restrictions on medication adherence, clinical outcomes, economic outcomes, and health care resource utilization. J Manag Care Spec Pharm. 2014;20(7):677-84. Available at: http://www.jmcp.org/doi/10.18553/jmcp.2014.20.7.677.

14. Suehs BT, Sikirica V, Mudumby P, Dufour R, Patel NC. Impact of a step therapy for guanfacine extended-release on medication utilization and health care expenditures among individuals receiving treatment for ADHD. J Manag Care Spec Pharm. 2015;21(9):793-802. Available at: http://www.jmcp. org/doi/10.18553/jmcp.2015.21.9.793.

15. Wagg A, Oelke M, Angulo JC, Scholfield D, Arumi D. Review of the efficacy and safety of fesoterodine for treating overactive bladder and urgency urinary incontinence in elderly patients. Drugs Aging. 2015;32(2):103-25.

16. Sanford M. Mirabegron: a review of its use in patients with overactive bladder syndrome. Drugs. 2013;73(11):1213-25.

17. U.S. Securities and Exchange Commission. Form 10K for Humana, Inc 2013. Available at: http://www.sec.gov/Archives/edgar/data/49071/ 000119312513069911/d446200d10k.htm. Accessed November 30, 2016.

18. Motheral BR, Henderson R, Cox ER. Plan-sponsor savings and member experience with point-of-service prescription step therapy. Am J Manag Care. 2004;10(7 Pt 1):457-64

19. Udall M, Louder A, Suehs BT, Cappelleri JC, Joshi AV, Patel NC. Impact of a step-therapy protocol for pregabalin on healthcare utilization and expenditures in a commercial population. J Med Econ. 2013;16(6):784-92.

20. Lu CY, Soumerai SB, Ross-Degnan D, Zhang F, Adams AS. Unintended impacts of a Medicaid prior authorization policy on access to medications for bipolar illness. Med Care. 2010;48(1):4-9.

21. Soumerai SB, Zhang F, Ross-Degnan D, et al. Use of atypical antipsychotic drugs for schizophrenia in Maine Medicaid following a policy change. Health Aff (Millwood). 2008;27(3):wl85-95.

22. Law MR, Ross-Degnan D, Soumerai SB. Effect of prior authorization of second-generation antipsychotic agents on pharmacy utilization and reimbursements. Psychiatr Serv. 2008;59(5):540-46.

23. Suehs BT, Louder A, Udall M, Cappelleri JC, Joshi AV, Patel NC. Impact of a pregabalin step therapy policy among Medicare Advantage beneficiaries. Pain Pract. 2014;14(5):419-26.

24. Pollack A. Drug goes from $\$ 13.50$ a tablet to $\$ 750$, overnight. The New York Times. September 20, 2015. Available at: http://www.nytimes. com/2015/09/21/business/a-huge-overnight-increase-in-a-drugs-price-raises-protests.html?_r=0. Accessed November 30, 2016.

25. Trefis Team. Why are generic drug prices shooting up? Forbes. February 27, 2015. Available at: http://www.forbes.com/sites/greatspeculations/2015/02/27/why-are-generic-drug-prices-shooting-up/print/. Accessed November 30, 2016.

26. Elsevier Clinical Solutions. Generic drug price increases: causes and impact. 2015. Available at: https://www.elsevier.com/clinical-solutions/ insights/resources/insights-articles/drug-information/whitepapers/whitepaperrising-generic-drug-prices. Accessed November 30, 2016. 
27. Schondelmeyer SW. Statement on why are some generic drugs skyrocketing in price? Statement given before the Senate Committee on Health, Education, Labor and Pensions (HELP). November 20, 2014. Available at: http://www.help.senate.gov/imo/media/doc/Schondelmeyer.pdf. Accessed November 30, 2016.

28. D'Souza AO, Smith MJ, Miller LA, Doyle J, Ariely R. Persistence, adherence, and switch rates among extended-release and immediate-release overactive bladder medications in a regional managed care plan. J Manag Care Pharm. 2008;14(3):291-301. Available at: http://www.jmcp.org/doi/ abs/10.18553/jmcp.2008.14.3.291.
29. Chancellor MB, Migliaccio-Walle K, Bramley TJ, Chaudhari SL, Corbell C, Globe D. Long-term patterns of use and treatment failure with anticholinergic agents for overactive bladder. Clin Ther. 2013;35(11):1744-51. 
APPENDIX Overall OAB Medication Utilization and Expenditures

\begin{tabular}{|c|c|c|c|c|c|c|c|c|c|c|c|c|}
\hline \multirow[b]{2}{*}{ Overall } & \multicolumn{12}{|c|}{ Month (Calendar Year 2013) } \\
\hline & 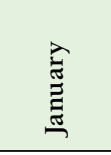 & 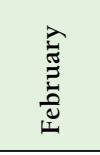 & 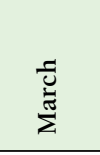 & $\overrightarrow{\bar{a}}$ & 产 & $\stackrel{\Xi}{\Xi}$ & $\stackrel{\lambda}{\Xi}$ & 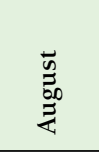 & $\begin{array}{l}\bar{\Xi} \\
\text { हूँ } \\
\text { ڤัँ } \\
\text { जั }\end{array}$ & $\begin{array}{l}\check{U} \\
\stackrel{0}{0} \\
\stackrel{0}{0}\end{array}$ & 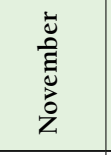 & 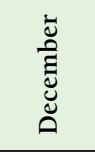 \\
\hline Member OAB Rx claims, $\mathrm{n}$ & 71,527 & 63,854 & 67,634 & 70,023 & 69,727 & 66,743 & 72,126 & 71,375 & 69,497 & 73,062 & 68,599 & 70,803 \\
\hline Number of OAB Rx claims, $\mathrm{n}$ & 77,263 & 67,348 & 72,561 & 75,449 & 75,665 & 70,926 & 78,713 & 77,137 & 74,269 & 79,388 & 73,286 & 76,897 \\
\hline Overall generic dispense rate, $\%$ & 58.0 & 59.2 & 59.6 & 60.6 & 60.2 & 61.1 & 60.7 & 60.7 & 61.0 & 61.3 & 61.8 & 62.0 \\
\hline Overall PUMPM ${ }^{a}$ & Baseline & $-7.1 \%$ & $-5.7 \%$ & $-4.8 \%$ & $-5.1 \%$ & $-5.8 \%$ & $3.3 \%$ & $5.5 \%$ & $4.4 \%$ & $6.1 \%$ & $2.3 \%$ & $4.1 \%$ \\
\hline Overall PUMPM $^{\mathrm{b}}$ & Baseline & $-6.1 \%$ & $1.7 \%$ & $0.5 \%$ & $-0.7 \%$ & $-0.5 \%$ & $9.4 \%$ & $2.4 \%$ & $-1.3 \%$ & $1.3 \%$ & $-3.6 \%$ & $2.7 \%$ \\
\hline
\end{tabular}

Note: Reporting is standardized in reference to January 2013 PUMPM drug spend and represents the change in PUMPM from baseline (January) PUMPM.

${ }^{a}$ Only members with utilization during the given month of observation are included in the PUMPM calculation. This includes the plan- and patient-paid components.

${ }^{b}$ Only members with utilization during the given month of observation are included in the PUMPM calculation. This includes the plan-paid components only.

$O A B=$ overactive bladder; $P U M P M=$ per utilizing member per month. 